
\title{
AFOSR 1480
}

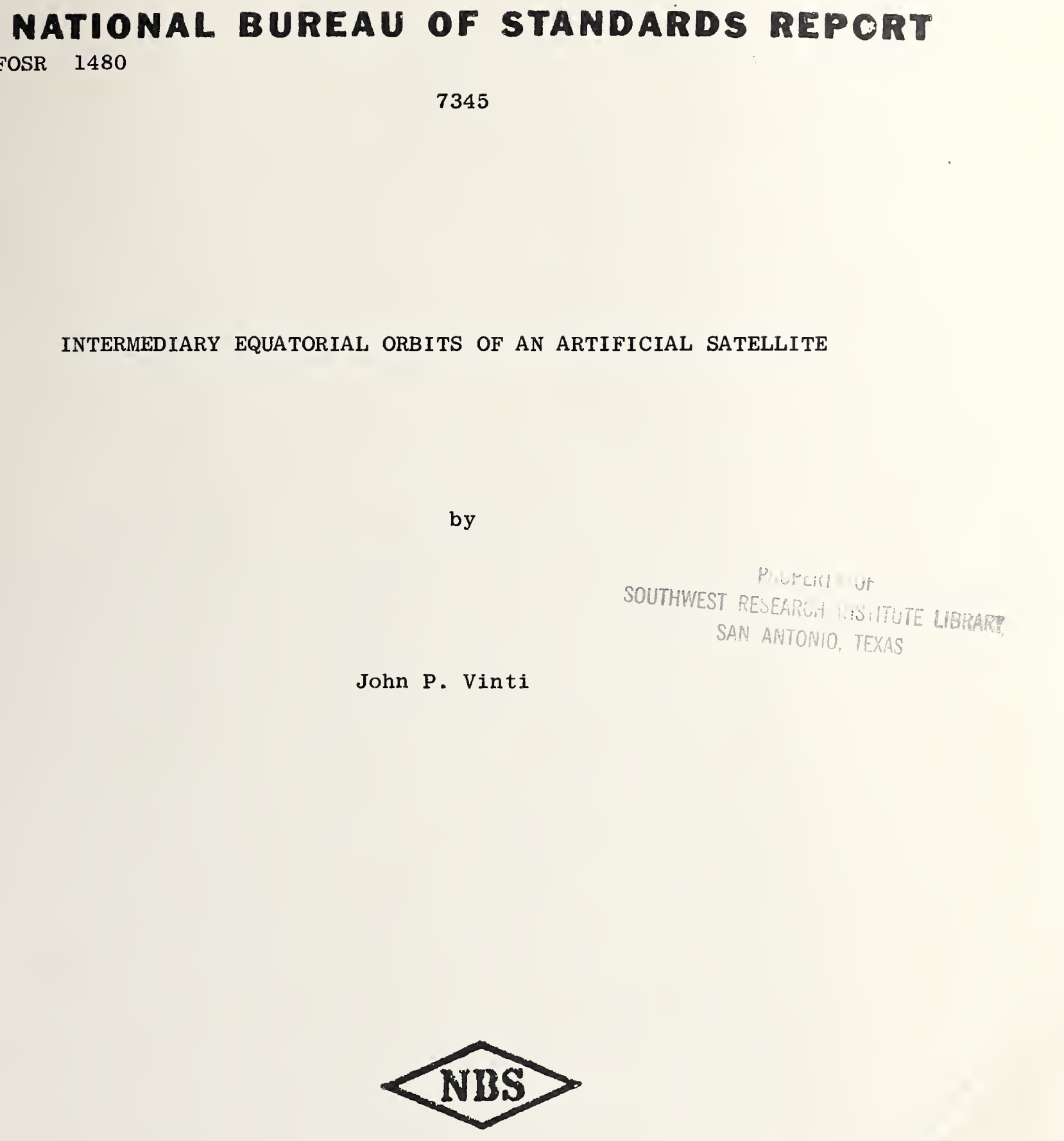

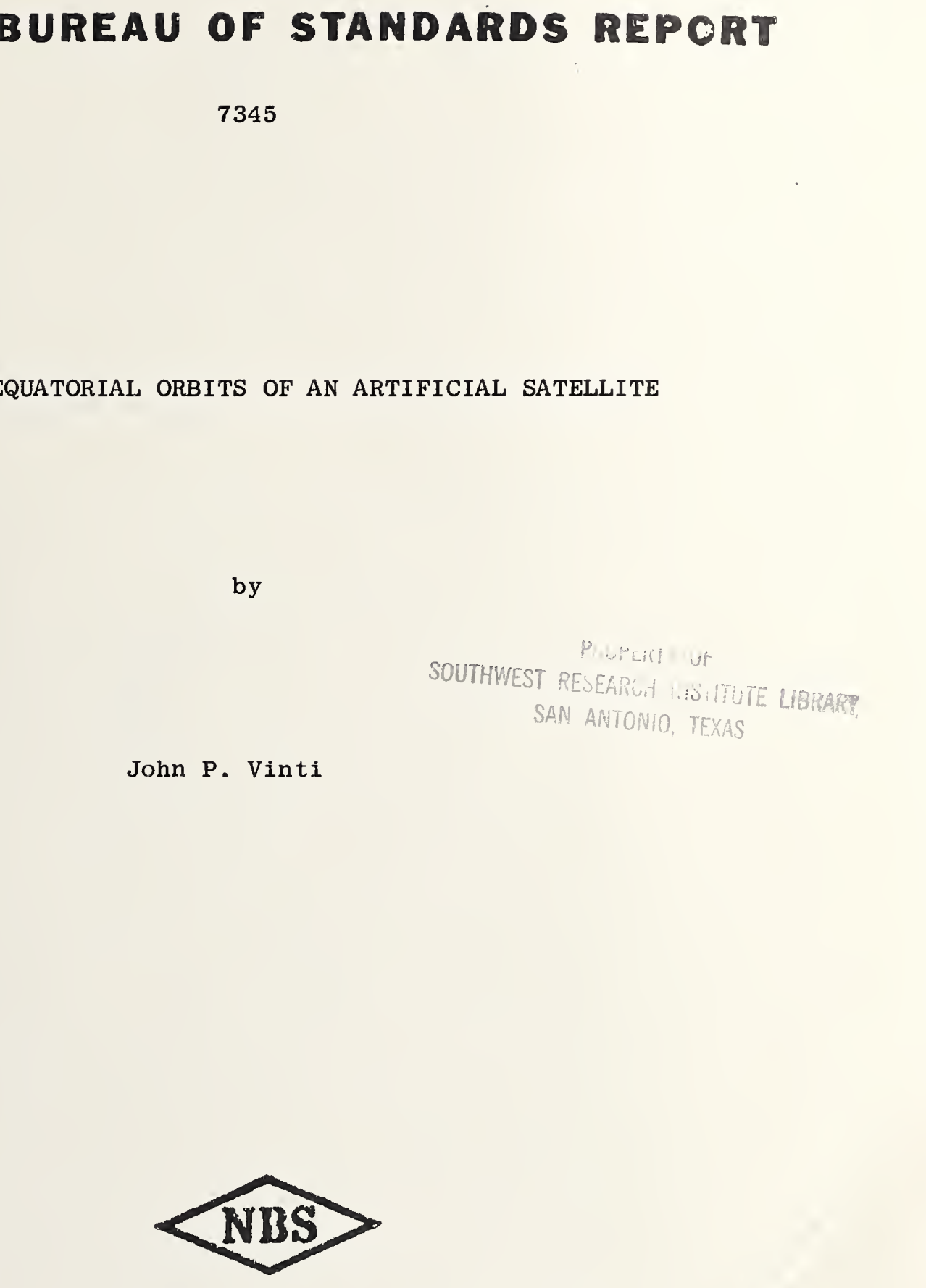

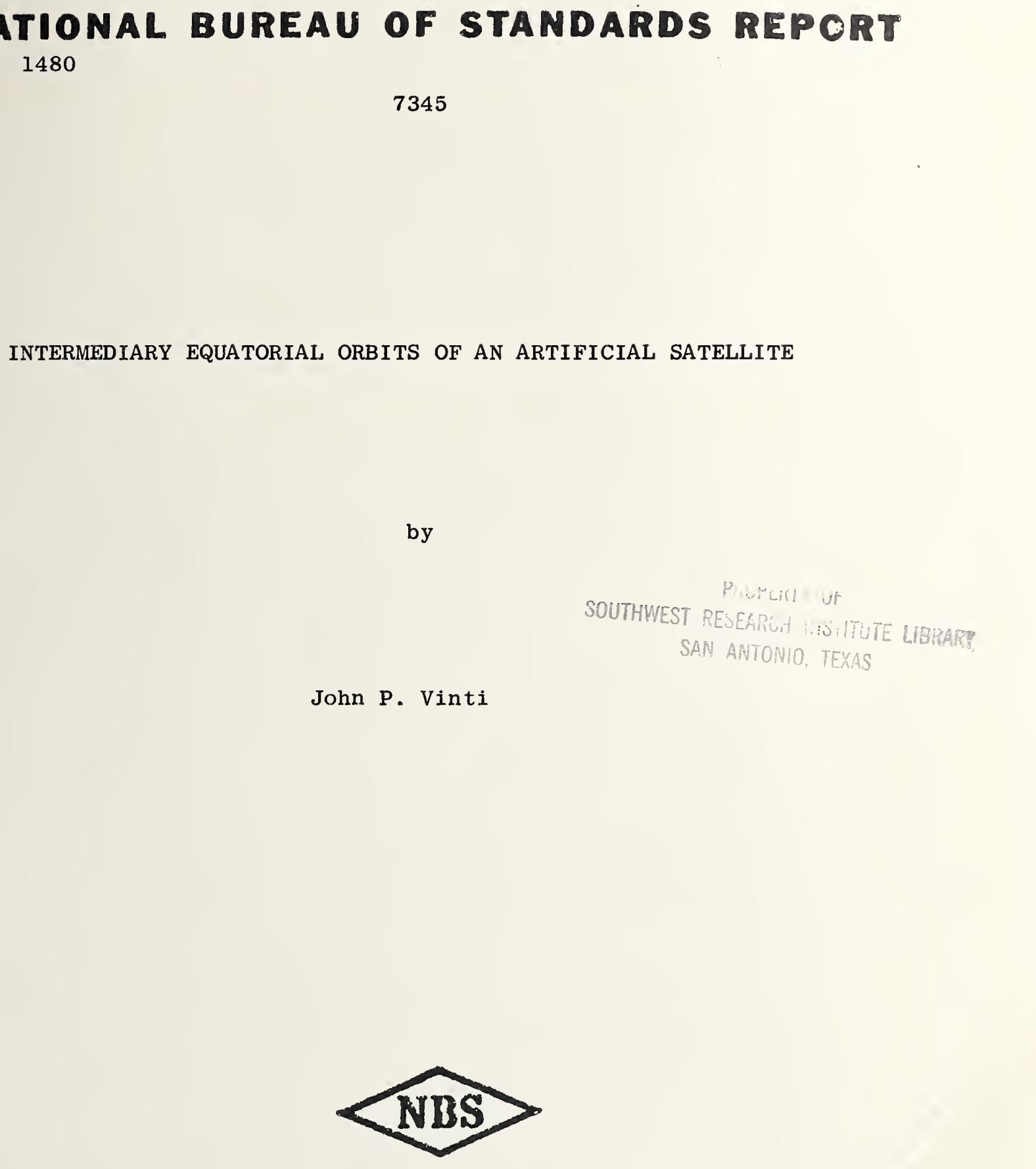

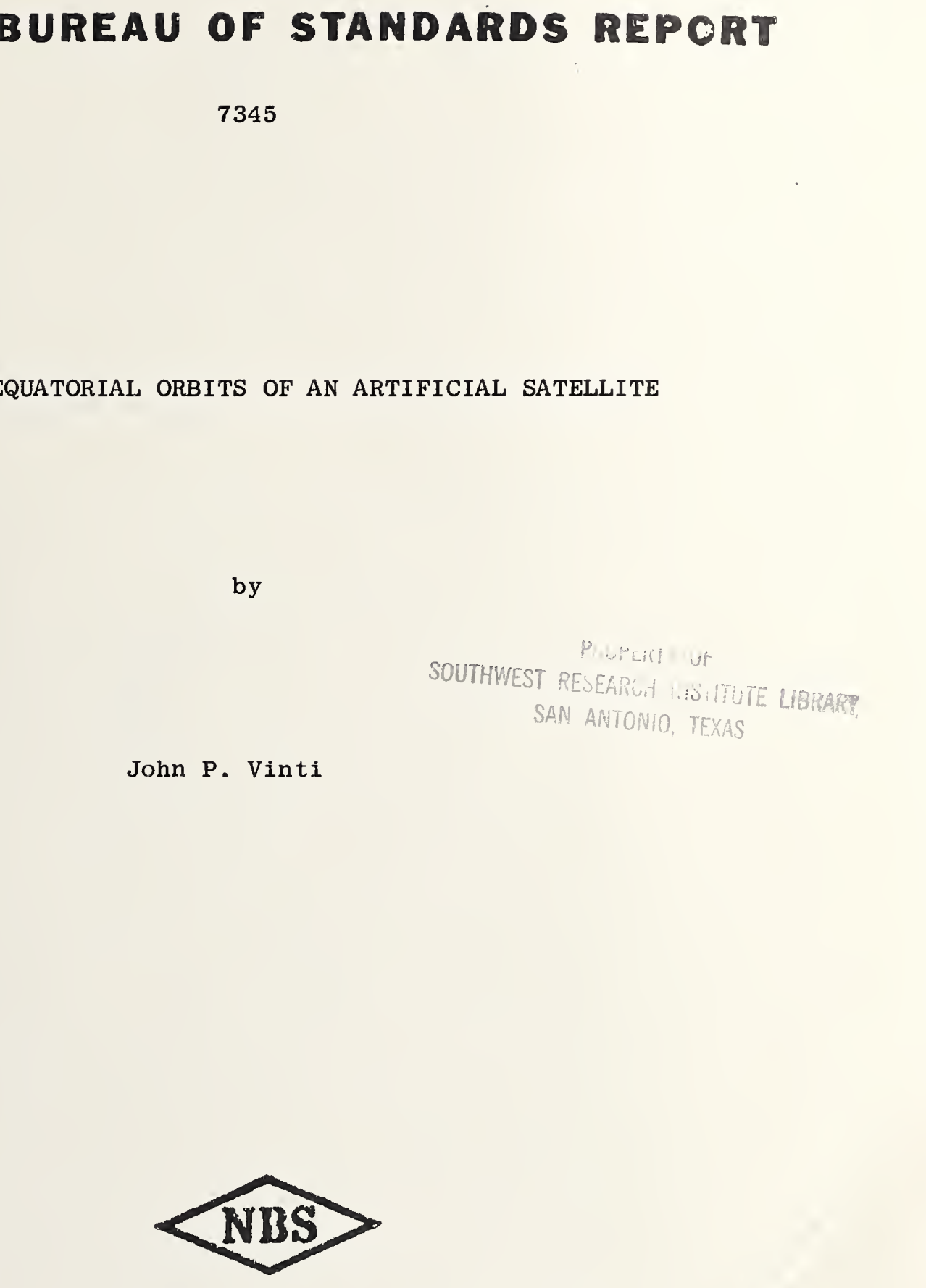

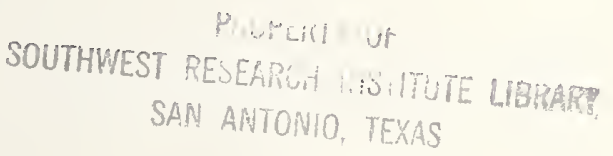

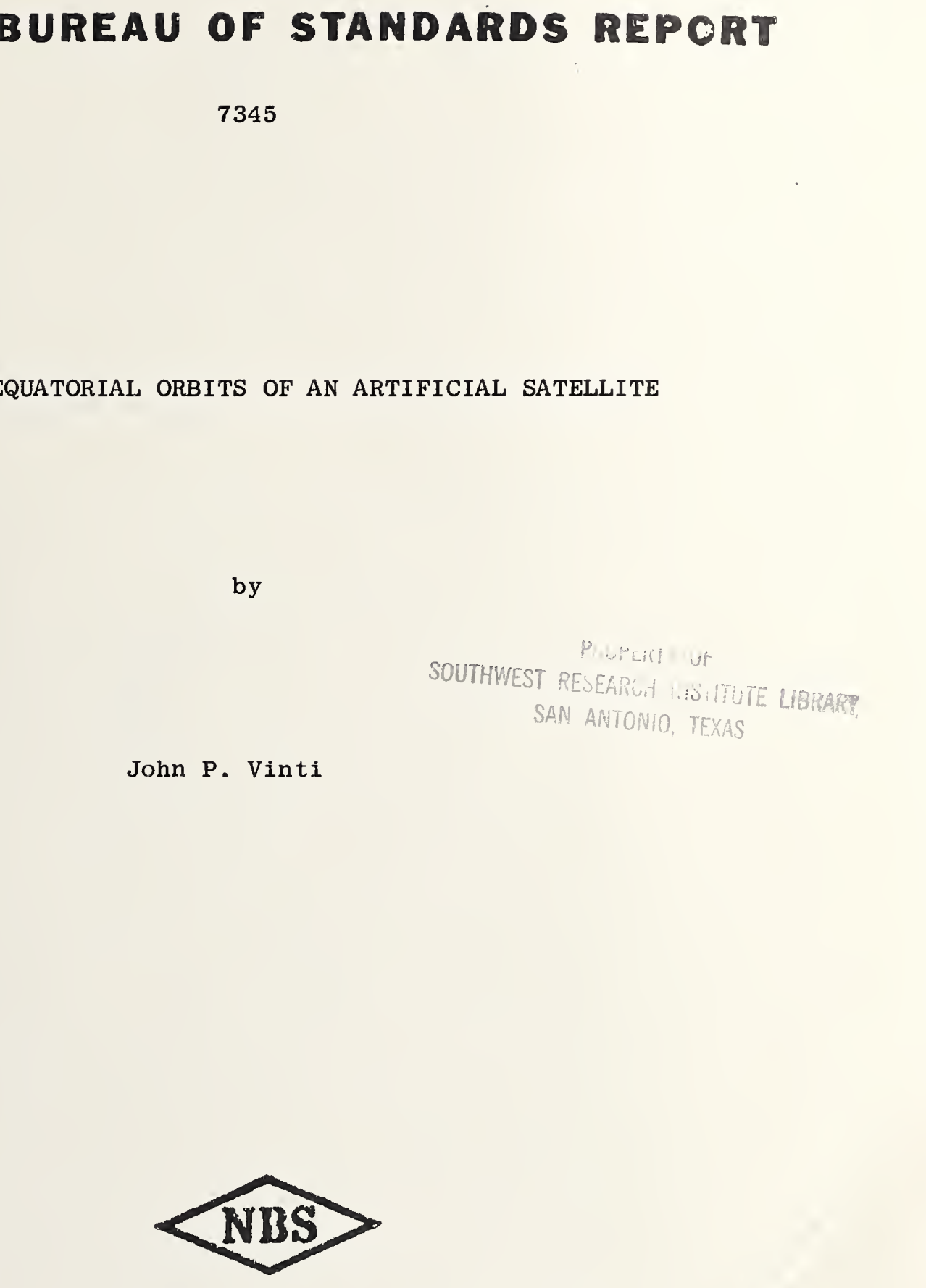

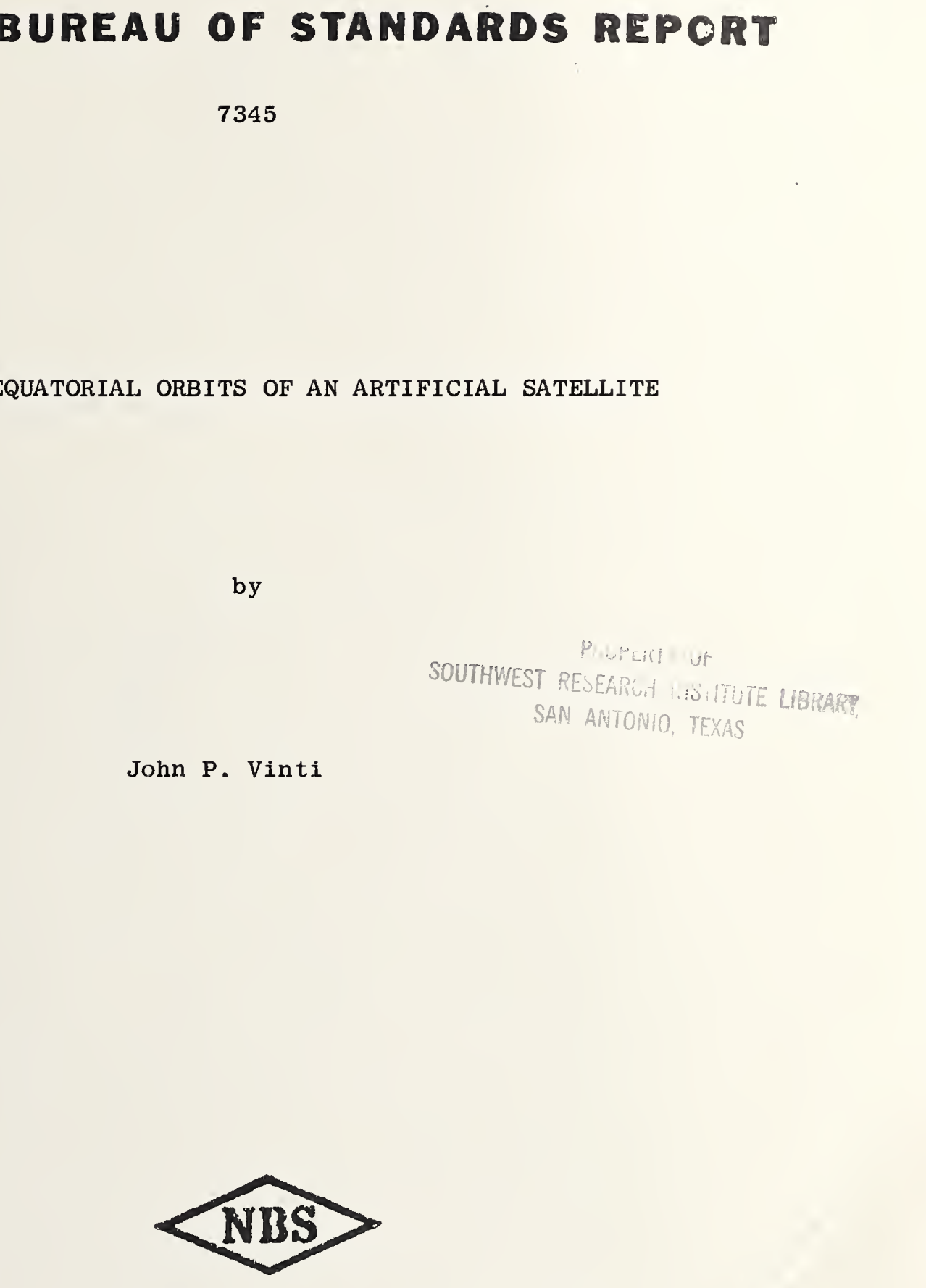

U. S. AEPARTMENT OF COMMERCE NATIONAL BUREAU OF STANDARDS 


\section{THE NATIONAL BUREAU OF STANDARDS}

\section{Functions and Activities}

The functions of the National Bureau of Standards are set forth in the Act of Congress, March 3, 1901, as amended by Congress in Public Law 619, 1950. These include the development and maintenance of the national standards of measurement and the provision of means and methods for making measurements consistent with these standards; the determination of physical constants and properties of materials; the development of methods and instruments for testing materials, devices, and structures; advisory services to government agencies on scientific and technical problems; invention and development of devices to serve special needs of the Government; and the development of standard practices, codes, and specifications. The work includes basic and applied research, development, engineering, instrumentation, testing, evaluation, calibration services, and various consultation and information services. Research projects are also performed for other government agencies when the work relates to and supplements the basic program of the Bureau or when the Bureau's unique competence is required. The scope of activities is suggested by the listing of divisions and sections on the inside of the back cover.

\section{Publications}

The results of the Bureau's research are published either in the Bureau's own series of publications or in the journals of professional and scientific societies. The Bureau itself publishes three periodicals available from the Government Printing Office: The Journal of Research, published in four separate sections, presents complete scientific and technical papers; the Technical News Bulletin presents summary and preliminary reports on work in progress; and Basic Radio Propagation Predictions provides data for determining the best frequencies to use for radio communications throughout the world. There are also five series of nonperiodical publications: Monographs, Applied Mathematics Series, Handbooks, Miscellaneous Publications, and Technical Notes.

A complete listing of the Bureau's publications can be found in National Bureau of Standards Circular 460 , Publications of the National Bureau of Standards, 1901 to June 1947 (\$1.25), and the Supplement to National Bureau of Standards Circular 460, July 1947 to June 1957 (\$1.50), and Miscellaneous Publication 240, July 1957 to June 1960 (Includes Titles of Papers Published in Outside Journals 1950 to 1959)( $\$ 2.25$ ); available from the Superintendent of Documents, Government Printing Office, Washington 25, D. C. 


\section{NATIONAL BUREAU OF STANDARDS REPORT NBS PROJECT

WATIONAL BUREAU OF STANDAI Approved for public release by the intended for use within the Goverr Director of the National Institute of listing of this Report, elther in who Standards and Technology (NIST) on the Office of the Director, National October 9, 2015. however, by the Government agenc. to reproduce additional coples for. ss accouming documenis published it is subjectod Juctlon, or open-llterature cobtained in writing from permlssion is not needed, red If that agency wishes

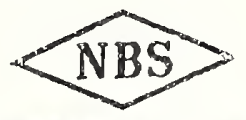

U. S. DEPARTMENT OF COMMMERCE NATIONAL BUREAU OF STANDARDS 
INTERMEDIARY EQUATORIAL ORBITS OF AN ARTIFICIAL SATELLITE ${ }^{1}$

by

John P. Vinti

A previous paper derived the solution for the drag-free motion of an artificlal satelite in the gravitational field of an oblate planet. The corresponding potential, expressed in oblate spheroidal coordinates, leads to separability and represents the even zonal harmonics exactly through the second, for any oblate planet, and approximately through the fourth, in the case of the earth.

The previous paper contained a restriction on the orbital inclination $I_{\text {, viz., }} I_{c}<I<180^{\circ}-I_{C}$, where $I_{c}$ might be as large as $I^{\circ} 54^{\prime}$ for an orbit sufficiently close to the earth. The present paper removes this restriction and shows that many of the formulae for the periodic terms may be simplified, when the orbit is equatorial or almost so. The results agree with those obtained by a direct two-dimensional solution, when the orbit is purely equatorial.

1. This work was supported by the U.S. Air Force, through the office of Scientific Research of the Air Research and Development Command. 


\section{Introduction}

This paper is a sequel to a recent paper ${ }^{2}$, concerning an accurate Intermediary orbtt for satelitte astronomy, and will accordingly follow the notation thereof. It there followed that 18

$$
\lambda \equiv b_{2} / b_{2}<1
$$

all the p-1ntegrals are expressibie in terms of rapldiy converging series Involving products of legendre polynomials with arguments $\lambda$ and $\left(1-e^{2}\right)^{-\frac{1}{2}}$. Condition (i) is equivalent to a restriction on the orbital incilination I. viz.,

$$
I_{c}<I<180^{\circ}-I_{c^{\circ}}
$$

where, to the first order in $\mathrm{k}$,

$$
\tan ^{2} I_{c}=k \equiv(r / p)^{2} J_{2}
$$

For the earth $J_{2}=0.00108$, so that for orbits so close that $p \approx r_{e}$

$$
I_{c}=1^{\circ} 54^{\circ}
$$

I Imposed the condition $\lambda<\mathbb{1}$ in order that

$$
\left(1+A p^{-1}+B p^{-2}\right)^{-\frac{1}{2}} \equiv\left(1-2 \lambda h+h^{2}\right)^{-\frac{1}{2}}
$$

should be a generating function for the Legendre polynomiais $P_{n}(\lambda)$. It now appears that such a restriction is unnecessary. Thus

$$
\left(1-2 \lambda h+h^{2}\right)^{-\frac{1}{2}}=\sum_{n=0}^{\infty} h^{n} P_{n}(\lambda)
$$

2. J.P. Vint1, J. Research National Bureau of Standards, 65B, 169-201, (1961), hereafter referred to as (A). Any reference in the present paper to an equation with decimal number, such as(5.30), denotes an equation in (A). 
even when $\lambda \geqq I$, provided only that ${ }^{(3)}$

$$
\mathrm{h}<\lambda-\left(\lambda^{2}-1\right)^{\frac{1}{2}}
$$

We need show only that(7) is always satisfied, in order that all the results of (A) hold for all orbtal inclinations. The oniy changes will be a few simplifications, especially for the cases $I=0^{\circ}$ or $180^{\circ}$ of purely equatorial orbits.

\section{The $\rho^{-}$Integrals}

To show that (7) is always satisfied when $\lambda \geqq 1$, note that

$$
\frac{b_{1}}{p}=\frac{b_{1}}{b_{2}} \frac{b_{2}}{p}=\lambda h
$$

By (4.12), (4.13), and (5.6) it follows that $b_{1}$ and $b_{2}$ are both real and non-negative for $c^{2}<$ ap, a relation that always holds for satellite orbits. Thus (7) is satisfied if and only if

$$
b_{1} / \rho<g(\lambda)
$$

where

$$
g(\lambda)=\lambda^{2}-\lambda\left(\lambda^{2}-1\right)^{\frac{1}{2}}
$$

We shall next show that

$$
I / 2<g(\lambda) \leqq 1 \quad(\lambda \geq 1)
$$

To show that $g(\lambda) \leqq 1$, note that for $\lambda \geqq 1$, we have $I>1-\lambda^{-2} \geqq 0$, so that $\left(1-\lambda^{-2}\right)^{\frac{1}{2}} \geqq 1-\lambda^{-2}, 1-\left(1-\lambda^{-2}\right)^{\frac{1}{2}} \leqq \lambda^{-2}$, and finally $\lambda^{2}-\lambda\left(\lambda^{2}-1\right)^{\frac{1}{2}} \leqq 1$. Thus $g(\lambda) \leqq 1$.

To show that $g(\lambda)>1 / 2$, note that for $\lambda \geqq 1$

$$
0 \leqq 1-\lambda^{-2}<\left(1-\frac{1}{2} \lambda^{-2}\right)^{2}
$$

3. E.W. Hobson, "The Theory of Spherical and Ellipsoidal Harmonics", page 15, Cambridge University Press, Cambridge 1931. 
so that

$$
\left(1-\lambda^{-2}\right)^{\frac{1}{2}}<1-\frac{1}{2} \lambda^{-2}
$$

or

$$
1-\left(1-\lambda^{-2}\right)^{\frac{1}{2}}>\frac{1}{2} \lambda^{-2}
$$

Then

$$
g(\lambda)=\lambda^{2}-\lambda\left(\lambda^{2}-1\right)^{\frac{1}{2}}>\frac{1}{2}
$$

as was to be shown.

From (9) and (11) it follows that when $\lambda \geqq 1$ the condition $b_{1} / \rho<1$ is necessary for the validity of (7) and that the condition $b_{1} / \rho<1 / 2$ is sufficient for its validity.

To show that $b_{1} / \rho<1 / 2$ for all bound ${ }^{(4)}$ orbits, note that $p \geqq \rho_{1}$, so that

$$
b_{1} / p \leqq b_{1} / \rho_{1}
$$

From the relation $\mathrm{c}^{2}=\mathrm{kp}^{2}$ and the relation $\rho_{1}=\mathrm{a}(1-\mathrm{e})$, $\mathrm{e} \leqq 1$, for a bound orbit, we then find from (3.25), (4.12), and (5.6) that

$$
\frac{b_{1}}{\rho_{1}}=\frac{k(1+e)\left(1-m_{0}^{2}\right)\left[1-k \eta_{0}^{2}\left(1-e^{2}\right)\right]}{\left[1-k\left(1-e^{2}\right)\right]\left[1-k \eta_{0}^{2}\left(1-e^{2}\right)\right]+4 k \eta_{0}^{2}}
$$

Here the numerator $\leqq k(1+e)$ and the denominator $\geqq(1-k)^{2}$, so that

$$
\frac{b_{1}}{\rho_{1}} \leqq \frac{k(1+e)}{(1-k)^{2}} \leqq \frac{2 k}{(1-k)^{2}}
$$

a function monotonic in $\mathrm{k}$ for $0<\mathrm{k}<1$.

For the earth $k<0.00108$, so that

$$
\mathrm{b}_{1} / \mathrm{p}_{1}<0.00216<\frac{1}{2}
$$

4. Past participle of the verb "to bind", taken from the terminology of atomic theory. 
From (16) and (19) 1t follows that for the earth

$$
b_{1} / p<1 / 2
$$

This is the condition sufficient for the validity of (7) and thus of the expansion (6), for a.1 $\lambda \geqq 1$.

AlI the developments of (A) then hold for the p-integrals, in particular (5.30) through (5.33) for the integral $R_{1}$, (5.35) through (5.40) for $R_{2}$, and (5.60) through (5.65) for $R_{3}$, where the $D_{m}{ }^{\prime}$ s are again given by $(5.50)$ and $(5.53)$.

To show the rapid convergence of the various series that there occur, we note first that since

$$
P_{n}(\lambda)=\pi^{-1} \int_{0}^{\pi}\left[\lambda+\left(\lambda^{2}-1\right)^{\frac{1}{2}} \cos x\right]^{n} d x
$$

and since $\lambda \equiv b_{1} / b_{2} \geqq 1$, we have

$$
\left(b_{2} / p\right)^{n} P_{n}(\lambda)=\pi^{-1} \int_{0}^{\pi}\left[b_{1} p^{-1}+p^{-1}\left(b_{1}^{2}-b_{2}^{2}\right)^{\frac{1}{2}} \cos x\right]^{n} d x
$$

Then

$$
\left|\left(\frac{b_{2}}{p}\right)^{n} P_{n}(\lambda)\right| \leqq\left[\frac{b_{1}}{p}+\frac{b_{1}}{p}\left(1-\lambda^{-2}\right)^{\frac{1}{2}}\right]^{n} \leqq\left(\frac{2 b_{1}}{p}\right)^{n}
$$

From (5.14) and (5.34) the series $S_{1}$ and $S_{2}$ that occur in the expressions for the $p$-integrals $R_{1}$ and $R_{2}$ are

$$
s_{j} \equiv \sum_{n=n}^{\infty}\left(\frac{-b}{p}\right)^{n} P_{n}(\lambda) \int_{0}^{v}(1+e \cos x)^{n-n} j d x, \quad(j=1,2)
$$

where $\mathrm{n}_{1}=2$ and $\mathrm{n}_{2}=0$. Thus 


$$
\begin{aligned}
\left|s_{j}\right| & \leqq v \sum_{n=n_{j}}^{\infty}\left(\frac{2 b}{p}\right)^{n}(1+e)^{n-n_{j}} \\
& \leqq v \sum_{n=0}^{\infty}\left(\frac{2 b}{p}\right)^{n+n} j(1+e)^{n} \leqq v\left(\frac{2 b}{p}\right)^{n} \sum_{n=0}^{\infty}\left[\frac{2 b 1}{p} \cdot(1+e)\right]^{n} \\
& \leq \frac{2\left(\frac{1}{p}\right)^{n} j}{2 b} \quad(j=1,2) \\
& \leqq-\frac{2 i}{p}(1+e)
\end{aligned}
$$

But $p=a\left(1-e^{2}\right)=\rho_{1}(1+e)$, so that by $(18)$

$$
b_{1} p^{-1} \leq k(1-k)^{-2}
$$

and

$$
2 b_{1}(1+e) p^{-1} \leqq 2 k(1+e)(1-k)^{-2} \leqq 4 k(1-k)^{-2}
$$

where $4 \mathrm{k}(1-\mathrm{k})^{-2}<0.0013$ for the earth. It follows that the series for $R_{1}$ and $R_{2}$, and thus the series for the secular coefficients $A_{1}$ and $A_{2}$, converge absolutely and more rapidly than a geometric series of common rat1o 0.0043 .

By $(5.49),(5.50)$, and $(5.53)$ the series $s_{3}$ that occurs in the expression for the p-integral $\mathbb{R}_{3}$ is

$$
\begin{aligned}
& s_{3}=s_{e}+s_{0} \\
& s_{e} \equiv \sum_{n=0}^{\infty} D_{2 n} \int_{0}^{v}(1+e \cos x)^{2 n+2} d x
\end{aligned}
$$




$$
\begin{aligned}
S_{0} & \equiv \sum_{n=0}^{\infty} D_{2 n+1} \int_{0}^{v}(l+e \cos x)^{2 n+3} d x \\
D_{2 n} & \equiv \sum_{j=0}^{n}(-1)^{n-j}(c / p)^{2 n-2 j}\left(b_{2} / p\right)^{2 j} P_{2 j}(\lambda) \\
D_{2 n+1} & \equiv \sum_{j=0}^{n}(-1)^{n-j}(c / p)^{2 n-2 j}\left(b_{2} / p\right)^{2 j+1} P_{2 j+1}(\lambda)
\end{aligned}
$$

From(33) and (23) and the relation $c^{2}=\mathrm{kp}^{2}$, it follows that

$$
\begin{aligned}
\left|D_{2 n}\right| \leqq k^{n} \sum_{j=0}^{n}\left(2 b_{1} / c\right)^{2 j} \leqq k^{n} \sum_{j=0}^{\infty}\left(2 b_{1} / c\right)^{2 j} \\
\leqq \frac{k^{n}}{\left.1-(2 b)_{1} / c\right)^{2}}
\end{aligned}
$$

and from (34) and (23) that

$$
\begin{aligned}
\left|\mathrm{D}_{2 \mathrm{n}+1}\right| \leqq \mathrm{k}^{\mathrm{n}}\left(2 \mathrm{~b}_{1} / \mathrm{p}\right) & \sum_{j=0}^{\mathrm{n}}\left(2 \mathrm{~b}_{1} / \mathrm{c}\right)^{2 j} \leqq k^{\mathrm{n}}\left(2 \mathrm{~b}_{1} / \mathrm{p}\right) \sum_{j=0}^{\infty}\left(2 \mathrm{~b}_{1} / \mathrm{c}\right)^{2 j} \\
& \leqq \frac{k^{\mathrm{n}}\left(2 \mathrm{~b}_{1} / \mathrm{p}\right)}{1-\left(2 \mathrm{~b}_{1} / \mathrm{c}\right)^{2}}
\end{aligned}
$$

Thus, by (3I) and (35)

$$
\begin{aligned}
\left|s_{e}\right| & \leqq \frac{(1+e)^{2} v}{1-\left(2 b_{1} / c\right)^{2}} \sum_{n=0}^{\infty}\left[k(1+e)^{2}\right]^{n} \\
& \leqq \frac{(1+e)^{2} v}{\left[1-\left(2 b_{1} / c\right)^{2}\right]\left[1-k(1+e)^{2}\right]}
\end{aligned}
$$


and by (32) and (36) that

$$
\begin{aligned}
\left|s_{0}\right| & \leqq \frac{(1+e)^{3} v\left(2 b_{1} / p\right)}{\left[1-\left(2 b_{1} / c\right)^{2}\right]} \sum_{n=0}^{\infty}\left[k(1+e)^{2}\right]^{n} \\
& \leqq \frac{(1+e)^{3} v\left(2 b_{1} / p\right)}{\left[1-\left(2 b_{1} / c\right)^{2}\right]\left[1-k(1+e)^{2}\right]}
\end{aligned}
$$

Then, by (30), (37), and (38), we have

$$
\left|s_{3}\right| \leqq \frac{(1+e)^{2} v\left[1+(1+e)\left(2 b_{1} / p\right)\right]}{\left[1-\left(2 b_{1} / c\right)^{2}\right]\left[1-k(1+e)^{2}\right]}
$$

But $p=p_{1}(1+e)$, so that by (18)

$$
2 b_{1} / p \leqq 2 k(1-k)^{-2}
$$

and

$$
2 b_{1} / c \equiv\left(2 b_{1} / p\right) k^{-\frac{1}{2}} \leqq 2 k^{\frac{1}{2}}(1-k)^{-2}
$$

Thus

$$
\left|S_{3}\right| \leqq \frac{(1+e)^{2} v\left[1+2 k(1+e)(1-k)^{-2}\right]}{\left[1-4 k(1-k)^{-4}\right]\left[1-k(1+e)^{2}\right]}
$$

The series for $S_{3}$ thus converges absolutely and more rapidly than the power series in $k$ of the function on the right side of (42), where $k<0.0011$ for the earth. On replacing $v$ by $\pi$, we can then say the same thing about the secular coefficient $A_{3}$.

3. Simpilfication of the p-Coefficients when $\lambda \geqq \mathbb{1}$

From $\lambda \equiv b_{1} / b_{2}$ it rollows that

$$
b_{2}=b_{1} \lambda^{-1} \leqq b_{1} \quad(\lambda \geqq 1)
$$


Since $b_{1}=O(k)$, it then follows that $b_{2}$ is also of order $k$ when $\lambda \geqq 1$. This fact enables us to simplify the coefficients $A_{1 n}$ and $A_{2 n}$, which are needed only to $O\left(k^{2}\right)$, and the coefficients $A_{3 n}$, which are needed only to $O(k)$.

Thus (5.32) and (5.33) lead to

$$
A_{11}=o\left(k^{3}\right) \quad A_{12}=O\left(k^{4}\right)
$$

$(5.39)$ and $(5.40)$ lead to

$$
A_{23}=O\left(k^{3}\right) \quad A_{24}=O\left(k^{4}\right)
$$

and (5.37) and $(5.38)$ lead to

$$
\begin{aligned}
& A_{21}=\left(1-e^{2}\right)^{\frac{1}{2}} p^{-1} e\left[b_{1} p^{-1}+\left(3-\lambda^{-2}\right) k^{2} \cos ^{4} I\right] \\
& A_{22}=\left(1-e^{2}\right)^{\frac{1}{2}} p^{-1} \frac{e^{2}}{8}\left(3-\lambda^{-2}\right) k^{2} \cos ^{4} I
\end{aligned}
$$

Here we have used

$$
\mathrm{b}_{1} \mathrm{p}^{-1}=\mathrm{k} \cos ^{2} \mathrm{I}+\mathrm{o}\left(\mathrm{k}^{2}\right)
$$

in the terms involving $b_{1}^{2} \mathrm{p}^{-2}$.

Similarly, for the coefficients $A_{3 n}$, which are needed only to $O(k)$, we obtain from (5.62) through (5.65)

$$
\begin{aligned}
& A_{31}=\left(1-e^{2}\right)^{\frac{1}{2}} \mathrm{p}^{-3} \mathrm{e}\left[2+\left(3+\frac{3}{4} e^{2}\right) \mathrm{k} \cos ^{2} \mathrm{I}-\left(4+3 \mathrm{e}^{2}\right) \mathrm{k}\right] \\
& \mathrm{A}_{32}=\left(1-\mathrm{e}^{2}\right)^{\frac{1}{2}} \mathrm{p}^{-3} \mathrm{e}^{2}\left[\frac{1}{4}+\frac{3}{4} \mathrm{k} \cos ^{2} \mathrm{I}-\left(\frac{\mathrm{e}^{2}}{4}+\frac{3}{2}\right) \mathrm{k}\right] \\
& \mathrm{A}_{33}=\left(1-\mathrm{e}^{2}\right)^{\frac{1}{2}} \mathrm{p}^{-3} \mathrm{e}^{3}\left[\frac{\mathrm{k}}{12} \cos ^{2} \mathrm{I}-\frac{\mathrm{k}}{3}\right) \\
& \mathrm{A}_{34}=-\left(1-\mathrm{e}^{2}\right)^{\frac{1}{2}} \mathrm{p}^{-3} \mathrm{e}^{4} \mathrm{k} / 32 \\
& -9-
\end{aligned}
$$


For $\lambda \geqq 1$ we need also to rewrite $(5.31),(5.36),(5.50)$, and $(5.53)$ for the secular coefficients $A_{1}, A_{2}, D_{2 n}$, and $D_{2 n+1}$, which all contain terms of the form $\left(b_{2} / p\right)^{m} P_{m}(\lambda)$. As sin I approaches zero, $b_{2}$ also approaches zero and $\lambda$ becomes infinite, so that such a term takes the indeterminate form zero times infinity. To remove this indeterminacy, note that

$$
\frac{b_{2}}{p} \equiv \frac{b_{2}}{b_{1}} \frac{b_{1}}{p} \equiv \frac{b_{1}}{p} \lambda^{-1}
$$

so that

$$
\begin{aligned}
\left(\frac{b_{2}}{p}\right)^{m} P_{m}(\lambda) & =\left(\frac{b_{1}}{p}\right)^{m} \lambda^{-m} P_{m}(\lambda) \\
& =\left(\frac{b_{1}}{p}\right)^{m} R_{m}\left(\lambda^{-1}\right)
\end{aligned}
$$

Here $R_{m}(x)$ is a function that has already appeared in (A), viz.,

$$
R_{m}(x) \equiv x^{m} P_{m}\left(x^{-1}\right)
$$

a polynomial of degree $[\mathrm{m} / 2]$ in $\mathrm{x}^{2}$.

To determine $\left(b_{2} / p\right)^{m} P_{m}(\lambda)$ for $\sin I=0$, first write

$$
P_{m}(\lambda)=\sum_{j=0}^{[m / 2]} \frac{(-1)^{j}(2 m-2 j) ! \lambda^{m-2 j}}{2^{m} j !(m-j) !(m-2 j) !},
$$

so that

$$
\begin{aligned}
R_{m}\left(\lambda^{-1}\right) & \equiv \lambda^{-m} P_{m}(\lambda)=1 \quad(m=0,1) \\
& =\frac{(2 m) !}{2^{m}(m !)^{2}}+\sum_{j=1}^{[m / 2]} \frac{(-1)^{j}(2 m-2 j) ! \lambda^{-2 j}}{2^{m} j !(m-j) !(m-2 j) !} \quad(m=2,3,4, \ldots)
\end{aligned}
$$


Thus

$$
R_{m}(0)=\frac{(2 m) !}{2^{m}(m !)^{2}}, \quad(m=0,1,2,3, \ldots)
$$

so that by (55) and (59)

$$
\left(\mathrm{b}_{2} / \mathrm{p}\right)^{\mathrm{m}} \mathrm{P}_{\mathrm{m}}(\lambda)=\frac{(2 \mathrm{~m}) !}{(\mathrm{m} !)^{2}}\left(\frac{\mathrm{b}_{10}}{2 \mathrm{p}}\right)^{\mathrm{m}}, \quad(\sin \mathrm{I}=0)
$$

where $b_{10}$ is the value of $b_{1}$ for $\eta_{0} \equiv \sin I=0$.

From (5.31), (5.36), (55), and (60) it then follows that

$$
\begin{array}{rlrl}
A_{1} & =\left(1-e^{2}\right)^{\frac{1}{2}} \sum_{n=2}^{\infty}\left(b_{1} / p\right)^{n} R_{n}\left(\lambda^{-1}\right) R_{n-2}\left(\sqrt{1-e^{2}}\right) & & (\lambda \geqq 1) \\
& =\left(1-e^{2}\right)^{\frac{1}{2}} \sum_{n=2}^{\infty} \frac{(2 n) !}{(n !)^{2}}\left(\frac{b_{10}}{2 p}\right)^{n} R_{n-2}\left(\sqrt{1-e^{2}}\right) & (\sin I=0) \\
A_{2}=\left(1-e^{2}\right)^{\frac{1}{2} p} \sum^{-1} \sum_{n=0}^{\infty}\left(b_{1} / p\right)^{n} R_{n}\left(\lambda^{-1}\right) R_{n}\left(\sqrt{1-e^{2}}\right) & (\lambda \geqq 1) \\
& =\left(1-e^{2}\right)^{\frac{1}{2} p} \sum_{n=0}^{-1} \frac{(2 n) !}{(n !)^{2}}\left(\frac{b}{2 p}\right)^{n} R_{n}\left(\sqrt{1-e^{2}}\right) & (\text { sin I I })
\end{array}
$$

Note that $A_{1}=O\left(k^{2}\right)$ and $A_{2}=O\left(k^{0}\right)$.

Then, from (5.61)

$$
A_{3}=\left(1-e^{2}\right)^{\frac{1}{2}} p^{-3} \sum_{m=0}^{\infty} D_{m} R_{m+2}\left(\sqrt{1-e^{2}}\right)
$$


where, by $(5.50),(5.53),(55),(60)$, and the relation $c^{2}=k p^{2}$, we find

$$
D_{2 n}=\sum_{j=0}^{n}(-1)^{n-j}(c / p)^{2 n-2 j}\left(b_{2} / p\right)^{2 j} P_{2 j}(\lambda)
$$

$$
\begin{aligned}
& =\sum_{j=0}^{n}(-1)^{n-j} k^{n-j}\left(b_{1} / p\right)^{2 j} R_{2 j}\left(\lambda^{-1}\right) \quad(\lambda \geqq 1) \\
& =\sum_{j=0}^{n}(-1)^{n-j} k^{n-j} \frac{(4 j) !}{[(2 j) !]^{2}} \quad\left(\frac{b_{10}}{2 p}\right)^{2 j} \quad(\sin I=0) \\
& D_{2 n+1}=\sum_{j=0}^{n}(-1)^{n-j}(c / p)^{2 n-2 j}\left(b_{2} / p\right)^{2 j+1} P_{2 j+1}(\lambda) \\
& =\sum_{j=0}^{n}(-1)^{n-j} k^{n-j}\left(b_{1} / p\right)^{2 j+1} R_{2 j+1}\left(\lambda^{-1}\right) \quad(\lambda \geqq 1) \\
& =\sum_{j=0}^{n-1}(-1)^{n-j} k^{n-j} \frac{(4 j+2) !}{[(2 j+1) !]^{2}}{\left(\frac{10}{2 p}\right)^{2 j+1}}_{(\sin I=0)}
\end{aligned}
$$

4. Simplification of Other Coefficients when $\lambda \geqq 1$

To simplify the $\eta$-coefficients when $\lambda \geqq 1$, we must first note that from page (176) of (A) we have

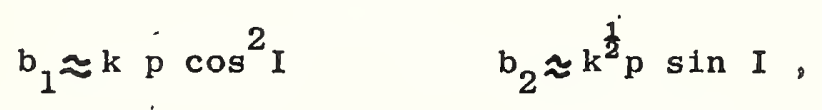

so that

$$
\lambda \equiv b_{1} / b_{2} \approx k^{\frac{1}{2}} \cos ^{2} I \csc I
$$


or

$$
\eta_{0} \equiv \sin I \approx k^{\frac{1}{2}} \cdot \lambda^{-1} \cos ^{2} I
$$

Thus

$$
\eta_{0}=O\left(k^{\frac{1}{2}}\right) \quad(\lambda \geqq 1)
$$

Also, since $\eta_{2}^{-I}=O\left(k^{\frac{1}{2}}\right)$, by $(3.42)$, 1t follows that

$$
q \equiv \eta^{/ / \eta}=o(k) \quad(\lambda \geqq 1)
$$

There also arises an indeterminacy in the $\eta$-coefficients, from the quantity $\left(\alpha_{2}^{2}-\alpha_{3}^{2}\right)^{-\frac{1}{2}} \eta_{0}$, which takes the form infinity times zero as

$\eta_{0} \equiv \sin I$ approaches zero. To remove this indeterminacy, use (4.15a), viz.,

$$
\alpha_{3}=\alpha_{2}\left(1-\frac{c^{2} \eta_{0}^{2}}{a_{0} p_{0}}\right)^{\frac{1}{2}} \cos I,
$$

to find

$$
\left(\alpha_{2}^{2}-\alpha_{3}^{2}\right)^{-\frac{1}{2}} \eta_{0}=\alpha_{2}^{-1}\left(1+\frac{c^{2}}{a_{0} p_{0}} \cos ^{2} I\right)^{-\frac{1}{2}}
$$

Then, from (8.27) and $(7.23)$

$$
\begin{gathered}
\psi_{s}=2 \pi \nu_{2}\left[t+\beta_{1}+\beta_{2} \alpha_{2}^{-1}\left(a+b_{1}+A_{1}\right) A_{2}^{-1}\right] \\
2 \pi \nu_{2}=\alpha_{2}\left(1+\frac{c^{2}}{a_{0} p_{0}} \cos ^{2} I\right)^{\frac{1}{2}} A_{2} B_{2}^{-1}\left(a+b_{1}+A_{1}+c^{2} \eta_{0}^{2} A_{2} B_{1} B_{2}^{-1}\right)^{-1}
\end{gathered}
$$

From $(8.33)$

$$
\psi_{0}=\left(-2 \alpha_{1}\right)^{-\frac{1}{2}} \alpha_{2}\left(1+\frac{c^{2}}{a_{0} p_{0}} \cos ^{2} I\right)^{\frac{1}{2}} A_{2} B_{2}^{-1} v_{0}
$$


From (8.37)

$$
\begin{aligned}
M_{1}= & \left(a+b_{1}\right)^{-1}\left[-\left(A_{1}+c^{2} \eta_{0}^{2} A_{2} B_{1} B_{2}^{-1}\right) v_{0}\right. \\
& \left.+\frac{c^{2}}{4}\left(-2 \alpha_{1}\right)^{\frac{1}{2}} \alpha_{2}^{-1}\left(1+\frac{c^{2}}{a_{0} p_{0}} \cos ^{2} I\right)^{-\frac{1}{2}} \eta_{0}^{2} \sin \left(2 \psi_{s}+2 \psi_{0}\right)\right],
\end{aligned}
$$

of order $\mathrm{k}^{2}$. Then, by (8.39)

$$
E_{1}=\left[1-e^{\prime} \cos \left(M_{S}+E_{0}\right)\right]^{-1} M_{1}
$$

since $M_{1}^{2}=o\left(k^{4}\right)$. Then $E_{1}$ and $v_{1}$ are both of order $k^{2}$. Also, by (8.40), $\psi_{1}=\left(-2 \alpha_{1}\right)^{-\frac{1}{2}} \alpha_{2}\left(1+\frac{c^{2}}{a_{0} p_{0}} \cos ^{2} I\right)^{\frac{1}{2}} B_{2}^{-1}\left[A_{2} v_{1}+A_{21} \sin \left(M_{s}+v_{0}\right)+A_{22} \sin \left(2 M_{s}+2 v_{0}\right)\right]$

$$
+\frac{q^{2}}{8} B_{2}^{-1} \sin \left(2 \psi_{s}+2 \psi_{0}\right)
$$

By $(8.45)^{\circ}, M_{2}$ and thus $E_{2}$ and $v_{2}$ are of order $k^{3}$ and, by $(8.48), \psi_{2}$ is aiso of order $\mathrm{k}^{3}$. Thus all the second-order periodic terms of (A) become of the third order and thus negligible, when $\lambda \geqq 1$.

By (8.50) the right ascension $\phi$ becomes

$$
\begin{aligned}
\phi=\beta_{3}+\alpha_{3} \alpha_{2}^{-1}(1 & \left.+\frac{c^{2}}{a_{0} p_{0}} \cos ^{2} I\right)^{-\frac{1}{2}}\left[\left(1-\eta_{0}^{2}\right)^{-\frac{1}{2}}\left(1-\eta_{2}^{-2}\right)^{-\frac{1}{2}} \chi+B_{3} \psi\right] \\
& -c^{2} \alpha_{3}\left(-2 \alpha_{1}\right)^{-\frac{1}{2}}\left(A_{3} v+\sum_{n=1}^{4} A_{3 n} \sin n v\right)
\end{aligned}
$$

Here we have dropped the periodic term $(3 / 32) \eta_{0}^{2} \eta_{2}^{-4}$ sin $2 \psi$ of $(8.50)$, since it is of order $k^{3}$ for $\lambda \geqq 1$. 


\section{Summary for $\lambda \geqq 1$}

For an almost equatorial orbit, corresponding to $\lambda \geqq 1$, the right ascension $\phi$ is given by (83). The spheroidal coordinates $\rho$ and $\eta$ are given by

$$
\begin{aligned}
\rho=a(1-e \cos E) & =(1+e \cos v)^{-1} p \\
\eta & =\eta_{0} \sin \psi
\end{aligned}
$$

Here the expressions

$$
E=M_{s}+E_{0}+E_{1} \quad v=M_{s}+v_{0}+v_{1} \quad \psi=\psi_{s}+\psi_{0}+\psi_{1}
$$

are sufficiently accurate to give the secular terms exactly and the periodic terms correctly through order $\mathrm{k}^{2}$, provided that $\mathrm{M}_{\mathrm{s}}$ is calculated by (8.24), $\psi_{S}$ by (77), $\mathrm{E}_{0}$ by $(8.31), \mathrm{E}_{1}$ by $(80)$ and $(81), \mathrm{v}_{0}$ and $\mathrm{v}_{1}$ by the anomaly relations $(8.1), \psi_{0}$ by $(79)$, and $\psi_{1}$ by (82).

6. The Case of a Purely Equatorial Orbit, $I=0^{\circ}$ or $180^{\circ}$

For $I=0^{\circ}$ or $180^{\circ}$ we have $\eta_{0}=0, \cos ^{2} I=1, X=\psi$ by $(6.51)$, $\gamma_{\mathrm{m}}=0$ by $(6.66)$,

$$
B_{3}=1-\left(1-\eta_{2}^{-2}\right)^{-\frac{1}{2}}
$$

by (6.65), and $\left|\alpha_{3}\right|=\alpha_{2}$, so that

$$
\alpha_{3} / \alpha_{2}=\operatorname{sgn} \alpha_{3}
$$

Then, by (83),

$\phi=\beta_{3}+\left(\operatorname{sgn} \dot{\alpha}_{3}\right)\left(1+\frac{c^{2}}{a_{0} p_{0}}\right)^{-\frac{1}{2}} \psi-c^{2} \alpha_{3}\left(-2 \alpha_{1}\right)^{-\frac{1}{2}}\left(A_{3} v+\sum_{n=1}^{4} A_{3 n} \sin n v\right)$

Also, by (8.24) with $\eta_{0}=0$,

$$
M_{s}=\left(-2 \alpha_{1}\right)^{\frac{1}{2}}\left(a+b_{1}+A_{1}\right)^{-1}\left(t+\beta_{1}\right)
$$


and by (77) and (78), with $\eta_{0}=0, \cos ^{2} I=I$, and $B_{2}=1$,

$\psi_{s}=\beta_{2}\left(1+\frac{c^{2}}{a_{0} p_{0}}\right)^{\frac{1}{2}}+\alpha_{2} A_{2}\left(1+\frac{c^{2}}{a_{0} p_{0}}\right)^{\frac{1}{2}}\left(a+b_{1}+A_{1}\right)^{-1}\left(t+B_{1}\right)$

Thus, by (87) and (88),

$\psi_{s}=\beta_{2}\left(1+\frac{c^{2}}{a_{0} p_{0}}\right)^{\frac{1}{2}}+\alpha_{2}\left(1+\frac{c^{2}}{a_{0} p_{0}}\right)^{\frac{1}{2}}\left(-2 \alpha_{1}\right)^{-\frac{1}{2}} A_{2} M_{S}$

Then, by (79) and (82), with $\eta_{0}=0$,

$$
\begin{gathered}
\psi_{0}=\alpha_{2}\left(1+\frac{c^{2}}{a_{0} p_{0}^{\frac{1}{2}}\left(-2 \alpha_{1}\right)^{-\frac{1}{2}} A_{2} v_{0}}\right. \\
\psi_{1}=\alpha_{2}\left(1+\frac{c^{2}}{a_{0} p_{0}}\right)^{\frac{1}{2}}\left(-2 \alpha_{1}\right)^{-\frac{1}{2}}\left[A_{2} v_{1}+\sum_{n=1}^{2} A_{2 n} \sin \left(n M_{s}+n v_{0}\right)\right]
\end{gathered}
$$

Addition of (89) through (91) then gives

$\psi=\beta_{2}\left(1+\frac{c^{2}}{a_{0} p_{0}}\right)^{\frac{1}{2}}+\alpha_{2}\left(1+\frac{c^{2}}{a_{0} p_{0}}\right)^{\frac{1}{2}}\left(-2 \alpha_{1}\right)^{-\frac{1}{2}}\left[A_{2} v+\sum_{n=1}^{2} A_{2 n} \sin \left(n M_{s}+n v_{0}\right)\right]$

Since $v=M_{S}+v_{0}+v_{1}$, where $v_{1}$ is of order $k^{2}$, and since $A_{21}$ and $A_{22}$ are of orders $k$ and $k^{2}$ respectively, it follows that

$$
\sum_{n=1}^{2} A_{2 n} \sin \left(n M_{s}+n v_{0}\right)=\sum_{n=1}^{2} A_{2 n} \sin n v
$$

to $\operatorname{order} \mathbf{k}^{2}$. Thus, to order $\mathbf{k}^{2}$,

$\psi=\beta_{2}\left(1+\frac{c^{2}}{a_{0} p_{0}}\right)^{\frac{1}{2}}+\alpha_{2}\left(1+\frac{c^{2}}{a_{0} p_{0}}\right)^{\frac{1}{2}}\left(-2 \alpha_{1}\right)^{-\frac{1}{2}}\left(A_{2} v+\sum_{n=1}^{2} A_{2 n}\right.$ sin $\left.n v\right)$ 
On inserting (94) Into (86), we then find

$$
\begin{gathered}
f=\beta_{3}+\beta_{2} \operatorname{sgn} \alpha_{3}+\alpha_{3}\left(-2 \alpha_{1}\right)^{-\frac{1}{2}}\left(A_{2} v+\sum_{n=1}^{2} A_{2 n} \sin n v\right) \\
-c^{2} \alpha_{3}\left(-2 \alpha_{1}\right)^{-\frac{1}{2}}\left(A_{3} v+\sum_{n=1}^{4} A_{3 n} \sin n v\right)
\end{gathered}
$$

It is a simple exercise to check these results for a purely equatorial orbit. To do so, let $X$ and $Y$ be the usual Cartesian coordinates, define $\rho$ and $\phi$ by

$$
X+1 Y=\left(\rho^{2}+c^{2}\right)^{\frac{1}{2}} \exp i \rho
$$

write down the kinetic energy $\frac{1}{2}\left(\dot{X}^{2}+\dot{Y}^{2}\right)$ in terms of $\rho$ and $\phi$ and their time derivatives, write the potential as $-\mu \rho^{-1}$, construct the Hamiltonian, and then write down the Hamilton-Jacobl equation. Separate the latter, to obtain the solution

$$
w=\alpha_{3} \phi \pm \int_{\rho_{1}}^{\rho}\left(\rho^{2}+c^{2}\right)^{-1} F(\rho)^{\frac{1}{2}} d \rho
$$

where

$$
F(\rho)=c^{2} \alpha_{3}^{2}+\left(\rho^{2}+c^{2}\right)\left(-\alpha_{3}^{2}+2 \mu \rho+2 \alpha_{1} \rho^{2}\right)
$$

The kinetic equations are then

$$
\frac{\partial W}{\partial \alpha_{1}}=t+\beta_{1}= \pm \int_{\rho_{1}}^{\rho} \rho^{2} F(\bar{\rho})^{\frac{1}{2}} d \rho
$$




$$
\begin{aligned}
\frac{\partial W}{\partial \alpha} & =\beta_{3}^{\prime}=\phi \mp \alpha_{3} \int_{\rho_{1}}^{\rho}\left(\rho^{2}+c^{2}\right)^{-1} \rho^{2} F(\rho)^{-\frac{1}{2}} d \rho . \\
& =\phi \mp \alpha_{3} \int_{\rho_{1}}^{\rho} F(\rho)^{-\frac{1}{2}} d \rho \pm c^{2} \alpha_{3} \int_{\rho_{1}}^{\rho}\left(\rho^{2}+c^{2}\right)^{-1} F(\rho)^{-\frac{1}{2}} d \rho
\end{aligned}
$$

On then following the procedure in (A), we find that $\rho$ is given by just the results of section 5 of the present paper, with $\eta_{0}$ placed equal to zero, and that is given by

$$
\begin{gathered}
\phi=\beta_{3}^{\prime}+\alpha_{3}\left(-2 \alpha_{1}\right)^{-\frac{1}{2}}\left(A_{2} v+\sum_{n=1}^{2} A_{2 n} \sin n v\right) \\
-c^{2} \alpha_{3}\left(-2 \alpha_{1}\right)^{-\frac{1}{2}}\left(A_{3} v+\sum_{n=1}^{4} A_{3 n} \text { sin } n v\right)
\end{gathered}
$$

Comparison of (102) with (95) shows that the results agree if

$$
\beta_{3}^{\prime}=\beta_{3}+\beta_{2} \operatorname{sgn} \alpha_{3}
$$

In the equatorial plane $r^{2}=\rho^{2}+c^{2}$, so that $r$ is at minimum whenever $\rho$ is at minimum. That is, the satellite is at perigee whenever $v=2 \pi \tau$, $\boldsymbol{T}=0,1,2, \ldots$. By (102) the right ascension $\phi_{\mathrm{p}}$ thus changes value from one perigee to the next. For an equatorial orbit about a planet of zero oblateness, however, the coefficient of $v$ in (102), viz.,

$\alpha_{3}\left(-2 \alpha_{1}\right)^{-\frac{1}{2}}\left(A_{2}-c^{2} A_{3}\right)$, would reduce to sgn $\alpha_{3}$, so that in such a limiting case

$$
\phi_{p}=\beta_{3}^{p}+2 \pi r \text { sgn } \alpha_{3},(r=0,1,2, \ldots)
$$


so that the actual position of perigee would remain fixed and $\beta_{3}$ would be its right ascension.

But for the case of a non-equatorial orblt around a planet of zero oblateness $B_{3}$ is simply the right ascenition $\Omega$ of the ascending node and $\beta_{2}$ is the argument $\omega$ of perigee. Thus for the $11 \mathrm{miting}$ case of a purely equatorial orbit about a planet of zero oblateness (103) would take the expected form

$$
\text { R.A. of perigee }=\Omega \pm \omega \text {. }
$$

where the sign would be plus for a direct orbit and minus for a retrograde orb1t. Thus the result (103) is reasonable. 
U. S. DEPARTMENT OF COMMERCE

Luther H. Hodges, Secretary

NATIONAL BUREAU OF STANDARDS

A. V. Astin, Director

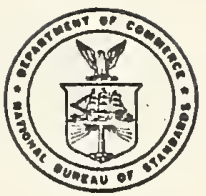

\section{THE NATIONAL BUREAU OF STANDARDS}

The scope of activities of the National Bureau of Standards at its major laboratories in Washington, D.C., and Boulder, Colorado, is suggested in the following listing of the divisions and sections engaged in technical work. In general, each section carries out specialized research, development, and engineering in the field indicated by its title. A brief description of the activities, and of the resultant publications, appears on the inside of the front cover.

\section{WASHINGTON, D.C.}

Electricity. Resistance and Reactance. Electrochemistry. Electrical Instruments. Magnetic Measurements. Dielectrics.

Metrology. Photometry and Colorimetry. Refractometry. Photographic Research. Length. Engineering Metrology. Mass and Scale. Volumetry and Densimetry.

Heat. Temperature Physics. Heat Measurements. Cryogenic'Physics. Equation of State. Statistical Physics. Radiation Physics. X-ray. Radioactivity. Radiation Theory. High Energy Radiation. Radiological Equipment. Nucleonic Instrumentation. Neutron Physics.

Analytical and Inorganic Chemistry. Pure Substances. Spectrochemistry. Solution Chemistry. Standart Heference Materials. Applied Analytical Research.

Mechanics. Sound. Pressure and Vacuum. Fluid Mechanics. Engineering Mechanics. Rheology. Combustion Controls.

Organic and Fibrous Materials. Rubber. Textiles. Paper. Leather. Testing and Specifications. Polymer Structure. Plastics. Dental Research.

Metallurgy. 'Thermal Metallurgy. Chemical Metallurgy. Mechanical Metallurgy. Corrosion. Metal Physics. Electrolysis and Metal Deposition.

Mineral Products. Engineering Ceramics. Glass. Refractories. Enameled Metals. Crystal Growth. Physical Properties. Constitution and Microstructure.

Building Research. Structural Engineering. Fire Research.' Mechanical Systems. Organic Building Materials. Codes and Safety Standards. Heat Transfer. Inorganic Building Materials.

Applicd Mathematics. Numerical Analysis. Computation. Statistical Engineering. Mathematical Physics. Operations Research.

Data Processing Systems. Components and Techniques. Digital Circuitry. Digital Systems. Analog Systems. Applications Engineering.

Atomic Physics. Spectroscopy. Infrared Spectroscopy. Solid Staie Physics: Electron Physics. Atomic Physics. Instrumentation. Engineering Electronics. Electron Devices. Electronic Instrumentation. Mechanical Instruments. Basic Instrumentation.

Physical Chemistry. Thermochemistry. Surface Chemistry. Organic Chemistry. Molecular Spectroscopy. Molecular Kinetics. Mass Spectrometry.

Office of Weights and Measures.

\section{BOULDER, COLO.}

Cryogenic Engineering. Cryogenic Equipment. Cryogenic Processes. Properties of Materials. Cryogenic Technical Services.

lonosphere Research and Propagation. Low Frequency and Very Low Frequency Research. lonosphere Research. Prediction Services. Sun-Earth Relationships. Field Engineering. Radio Warning Services.

Radio Propagation Engineering. Data Reduction Instrumentation. Radio Noise. Tropospheric Measurements. Tropospheric Analysis. Propagation-Terrain Effects. Radio-Meteorology, Lower Atmosphere Physics.

Radio Standards. High Frequency Tlectrical Standards, Radio Broadcast Service. Radio and Microwave Materials. Atomic Frequency and Time Interval Standards. Electronic Calibration Center. Millimeter-Wave Research. Microwave Círcuit Standards.

Radio Sysiems. High Frequency and Very High Frequency Research. Modulation Research. Antenna Research. Navigation Sysiems.

Upper Atmosphere and sipace Physics. Upper Atmosphere and Plasma Physics. Ionosphere and Exosphere Scatter. Airglow and Aurcra. Konospheric Radio Astronomy. 
